\title{
The Subject Specialist
}

Thomas Franklin Currier, late associate librarian, Harvard College Library, now honorary consultant in American Literary Bibliography in the University Library.

T $\mathrm{T}$ Is the purpose of this paper to discuss I a somewhat different organization of work from that to which we are accustomed in our university libraries. This organization should provide sympathetic service to those engaged in scholarly researches, reduce the cost of administration, speed the processes of accessioning, and benefit the staff by giving to those with proper equipment and experience a larger share in the development and use of the collections under their care. It is a study of how far it is practicable to substitute a division of work by subject for the hitherto almost universal practice of division by process (order, accessions, cataloging, classification, and reference). This study applies almost exclusively to the organization of work in large university libraries, specializing in diverse fields of knowledge, and acquiring books in many languages. The paper is based on actual experiments over a period of a number of years in attempts to make such organization practically effective.

An example, one of many that might be cited, will show the type of problem that has led to the conclusions here expressed. Some years ago, although my administrative duties were theoretically limited exclusively to cataloging and classification, it came my way to have the spending of a moderate sum to be devoted to unusual books in the field of the history of education. Because I held the purse-strings I was consulted by the order chief as to purchasing a rare and somewhat costly, anonymous, sixteenth-century publication. A letter from our Italian agent was referred to me, describing the publication at length, and providing useful and rather unusual bibliographical references. In the course of making the decision as to purchasing the book, exact knowledge as to its significance and position in the history of education was acquired. This knowledge was sufficient, had I had the book in hand, to enable me to catalog and classify it with practically no additional research. I approved the purchase and put the matter out of my mind. Some time later, glancing at a pile of newly acquired books, my eye lit on one that looked particularly interesting. Behold, it was the treatise I had earlier approved; it had now been received, accessioned, and sent on in regular course for cataloging. Had I not accidentally noticed the book on the table it would have been the subject of a new investigation on the part of the cataloger, pursued without the advantage of reading the agent's letter. The chances are that lacking the information contained in this letter the results of the new investigation would not have been so precise, and there would surely have been an unnecessary expenditure of time in searching biographical dictionaries, bibliographies, and other sources. In brief, the first re- 
search, devoted to deciding if the book should be purchased, would have been wholly lost, so far as cataloging and classification were concerned. Is this not an altogether too common occurrence in our libraries?

\section{One Investigation Adequate}

I well know the usual reply to my problem. The order slip might easily have been marked with the statement that a bibliographical letter regarding the book was available in the order department files, and this note might have been passed on to the cataloger, or I might, at the beginning, have asked that the book be sent directly to me on receipt. The fact remained that neither of these seemingly obvious steps was taken, and it remains true that, even where there is the utmost desire on the part of all to coordinate order and catalog work, such matters are seldom automatically attended to. A spurt may be made in this direction as a result of a chance conference between department heads, or as a consequence of some flagrant case, and printed forms may be evolved to simplify the passing on of information; in six months' time the procedure has fallen quietly into discard. If, however, the information acquired in purchasing is passed on to the cataloger, the latter must usually, even then, repeat for herself the survey of sources in order to catalog the book properly, and as a consequence, we pay for two investigations of the same item by two competent persons, when one would have been wholly adequate.

Under the plan here suggested, whenever the library possesses a live and growing special collection, a trained and competent person should be placed in charge. This assistant should herself check all orders for books in this field, and know how much money may be spent ; she might, to some extent, be authorized to initiate orders, guided as to policy by the librarian or the faculty member who may have been delegated to advise on purchases. The special assistant should invariably, herself, as soon as possible, receive the books she has ordered, and supervise the classification and cataloging. Who afterwards can better guide the visiting research specialist or reply to correspondence from outside relating to her subject? I may well quote here from a recent preface:

To Miss Ruth Cook of the Architectural Department and Miss Louise Taylor of Widener I am very grateful. Their assistance has been much more than directing me to books on architecture and education treating the school-building problem. Each in a lovely and personal way has entered into the spirit of this investigation, and has been a genial counselor.

\section{Lost Motion}

I am not fighting windmills. I have watched for years the lost motion in work done under a strictly process department system in a large, scholars' library, and this when ( $\mathrm{I}$ assure you) there have been the best intentions in the world on the part of the staff personnel. In fact, it is just where these intentions are the best that we occasionally notice the greatest waste of time in conferences between subordinates, or of effort on the part of someone, spent in writing long memoranda in a laudable attempt to pass on information. In a certain proportion of cases these memoranda are helpful, but too often they recite matters that are well known or, at the most, easily discovered by the cataloger, expert in her field.

Turn, for a moment, to the use made of library material after acquisition and cata- 
loging. It will happen, at times, that a cataloger, who may be something of a specialist, is asked to check on a request for data after some research has been made by a member of another department, less familiar with the sources of information in the field in question. The normal procedure would be to report the results back to the department to which the request was first addressed, to be communicated to the original seeker for information. When this procedure becomes habitual, what is more discouraging to an ambitious cataloger than to supply information regularly to the library patrons always through a third person, thus losing the pleasure and, decidedly, the benefit that comes from direct contact with the one who asks for help? How encouraging to the cataloger, on the other hand, to have her helpfulness recognized in a neatlyworded preface!

It is, then, wise to give the competent and technically trained specialist on the library staff a larger share of responsibility in all that pertains to her subject, including checking and approving orders, cataloging, classification, and making the collections useful, particularly to those engaged in advanced research. Each of the processes thus mentioned benefits hugely when carried on in close and intimate conjunction with the others.

\section{Axiomatic Propositions}

Consider now this question from the angle of administrative costs. May we not start by looking on certain propositions as axiomatic and then consider their effect on our library routine?

First, the cost per unit of acquiring and absorbing difficult material is enormously greater than that for simple material. It may cost several dollars (anywhere from three to thirty or more) to purchase and catalog an incunable, while it will cost as many cents to do the same for a current American novel. Moreover, the worker who can do independent and wholly satisfactory work on incunables is of a rare type, difficult to find and retain, while American fiction can be acquired and absorbed, with complete satisfaction, by the newest library school graduate. As to cost, any administrator of cataloging knows the ease with which production figures are swollen when the staff is devoting its time to mass production of simple material, particularly when it is in English. Unfortunately for those who pay the bills the most important work of the scholars' library is apt to deal with difficult material, where mass production may be impossible and where centralized cataloging is not available. In spite of this situation it is altogether too easy for the administrator to base the routing of work on a study of mass production of homogeneous or easy material rather than on what we might call "quality" production of the difficult.

Our second axiom might be, that when acquiring and absorbing difficult material, the salary cost of the labor involved is less when one expert person passes the books and pamphlets through all but the mechanical processes than it will be if they are passed successively, like a Ford car in the making, from one expert to another. That is to say, automobile factory methods do not apply, in the scholars' library, to that part of the administrative routine that demands reasoning ability and a knowledge of the subject. The example of the rare treatise on education which $I$ cited at the beginning of this study makes this evident. Furthermore, successive handling of such material by several ex- 
perts in a large staff is not alone unduly expensive but too often leads to clashing of personalities, and, in the end, to lack of uniformity in general results.

Our third axiom would state that the initial sorting of a large and, particularly, of a miscellaneous collection, should be done by an experienced expert, and not by young and inexperienced members of the staff. My own best object lesson for this came with the receipt of the library of Evert J. Wendell, when we unpacked case after case of books and pamphlets, thousands of them. An attempt was made to set younger persons at the initial sorting of the unique and enormous lots of pamphlets. After a few days of unsuccessful attempts, I gave up and devoted my own evenings for a week to the work, personally handling each individual item. By the time I had finished I knew that collection and had already made plans for the final disposition of the component parts and for the method of treatment. After gaining so complete a knowledge of the material and of the possibilities in the routine of handling it, it would have been little less than criminal to have turned it over to another department head for further investigation and treatment. ${ }^{1}$

\section{The Subject Specialist and Technical Processes}

From these statements it follows, first, that one expert specialist should supervise the progress of a special collection, or of difficult material, from the very inception of the order and the receipt of a collection through the processes of acquisition and absorption; and second, this specialist must, for economy's sake, be,-not only conversant to the necessary degree with

1 This matter has been treated at greater length in an article in the June, 1940, number of College and Research Libraries. her subject, but must be technically trained and experienced in the various library processes, and, moreover, actually engaged in, or supervising, the daily routine of cataloging and classifying in the subject.

Cataloging and classification have been set aside too much as special processes, cleanly separated from the other library processes, such as order and reference work. Because a person is called a "cataloger" it is too frequently implied that she can have no share in reference and order work even in her own specialty. We who administer agree that it requires a high degree of intelligence and ability to catalog and classify, and then we deaden the work and limit the possibilities of an intelligent person employed to do this work, by withholding stimulating contacts with the faculty, research workers, and others. Furthermore, we avoid giving to her the slightest share or responsibility in the building up of the collections in her care, failing to use her even for so simple but necessary a task as checking orders for books in her field.

A bit of reminiscence may serve here. Some years ago, when we were keeping rather careful figures on cost, our Russian cataloger (now no longer on our staff) was, by exception, finally entrusted with the duty of placing Russian orders and carrying on correspondence in regard to them. At the end of the year a summary of statistics, covering twelve months' work, showed that the cost per title of her work, including ordering, was precisely the same as the cost per title of the remainder of the staff that was engaged simply in cataloging and classifying. Moreover, where she formerly had been rather impatient at some of the necessary and seemingly petty rules of cataloging, she now, herself, of her own initiative, 
followed them intelligently and with discrimination, having been impressed, through her order work, by their necessity. The purchase of an expensive duplicate taught her more quickly and thoroughly than a thousand rules the necessity of certain reference cards and the reasons for our methods of handling bilingual titles.

\section{The Ideal Organization}

What, then, is the ideal organization which will meet the situation thus presented? In considering this it will be kept in mind that when special subject supervisors are appointed it must be only for those fields of research in which the library's collections are active, and steadily - increasing; and, second, that in any field thus selected for special treatment the subject supervisor will have assistants in large enough number to handle competently the work in the manner to be outlined. Outside of the special subjects for which provision is thus made, there will be a broad fringe of subjects for which books and pamphlets are being steadily acquired, but not in sufficient quantity to warrant a special organization for each topic. A special organization, furthermore, is unnecessary for these because the material acquired will consist largely of current publications and chance accessions. To cover this area of miscellaneous topics and to handle the general machinery of the library there must always exist the normal "process" departments: order, reference, rare book, serial, cataloging, and others as needed. It is not possible to imagine the whole library staff efficiently divided into little compartments on a basis of one for each and every subject in the whole realm of knowledge, with a somewhat independent supervisor for each. The subject supervisor organi- zation is, so to speak, superimposed on the "process" organization now ordinarily adopted. How would the plan work out?

\section{The Plan in Action}

The order department would maintain an intimate knowledge of the application of the book funds and see that they are appropriately allocated; it would prepare a buying budget and keep such accounts as are necessary to guard against overstepping the approved budget; it would carry on the correspondence and promote business contacts with agents and bookdealers, although in exceptional cases (e.g. Russian) the contact with definite dealers might be more simply placed in the hands of the subject specialists; the order department would normally send off orders and check invoices; it would keep an eye on book prices; it would check current publications, with a view to purchase, except where this duty might more economically be assumed by the subject supervisor or, in the university library, be the labor of love and duty of a faculty member. In the matter of checking invoices and maintaining a record of pending orders and of uncataloged material there must be close coordination between the subject supervisor and the order department, to avoid duplication of records and labor. In precise subjects and for collections in the lesser-known languages the subject supervisor might well maintain the sole file of pending orders and uncataloged material, thus having it always close at hand for ready and speedy reference. She would, in consequence, assume the entire responsibility of checking orders to prevent the purchasing of duplicates. To these specialists the order department would, ultimately, refer all orders in their respective fields. 
The reference staff would receive the mass of questions addressed to it by students, visitors, and the teaching body, or coming by mail. It should endeavor, always, to divert to the subject specialists unusual questions, to introduce to them the research visitor, and pass on, to be answered by the subject assistants, letters definitely in their respective provinces. It is probable that this correspondence should be visaed by the superior officer to whom reference will be made later.

There should be a body of catalogers and classifiers, apart from the subject supervisors and their assistants, always available for the general and miscellaneous work, and for mass production. This staff and its chief would be responsible for the upkeep of the catalogs, the maintenance of uniform practice, and the harmonious development of the classification scheme. Furthermore, it should serve to coordinate the work of the subject supervisors where the several fields impinge, and furnish special help when one or another of the subject specialists receives an abnormal influx of books.

This brings us to a more detailed survey of the work of this body of subject specialists or supervisors for which this paper is a plea. The members of this staff, closely integrated with all the process departments, must not only know a good bit about their subjects and the library's collections, but must be competent as workers or supervisors in the processes of cataloging and classification and engaged daily in these processes. They will translate, so to speak, the books and pamphlets received into terms of library practice. I do not say there is not room, when occasion demands, for having at the head of a special subject a scholar of competence and reputation; but when this is advisable he would not be asked to concern himself with minute technical details. He must have as his right hand a librarian specialist, trained in the library technique, who will carry out the routine, and act in his absence.

The normal, technically-trained, subject specialist need not, even in a university library, be the holder of a doctor's degree. In fact, it too frequently happens that the holder of this degree is not desirous of remaining for a long period as one wheel of a large library machine, when he is of the really competent type demanded for the work in question. In a library position he frequently is intolerant of the minutiae of the work of cataloging, classification, toilsome checking of orders, and the like. He often looks on the library position as a potboiler for the, to him, more essential work of original research and authorship.

\section{Usefulness Will Grow}

To a person, on the other hand, holding the bachelor's or master's degree, there is much inspiration in a library position that entails the responsibility of caring for, developing, and making useful notable collections in some important field of research. In a university library, such a person with moderate attainments in her chosen field will always have some interested member of the faculty to guide and inspire and even incite her to continued personal study. Thus her usefulness will grow with the years; for the best service in university library work demands full knowledge of the collections and experience in handling them. Given a person of this type, guided by a faculty member and assigned to a live and growing subject, she should be conversant with and direct all important work that goes on in the li- 
brary within her field, drastic innovations in her work and abnormal matters being taken up with the advice and consent of her superior. The specialist should be in a position to initiate orders for books, and should check or pass on the checking of all orders in her particular subject. As soon as possible upon receipt, books and pamphlets in her subject should be sent to her desk and she should supervise the details of cataloging and classifying these books and pamphlets. In case of an unusual quantity of accessions she should be assigned help, to be applied under her own supervision. As to reference work, she would not be bothered with routine questions that can be answered with perfect assurance by the regular reference staff, but investigators starting work in her field should meet her, unusual questions should be turned her way, and correspondence in her subject be referred to her. If she is competent the members of the teaching staff of the university will speedily find their way to her desk.

\section{The Subject Specialist and the Investi- gator}

It should be made clear that these subject specialists will by no means be appointed with the view of teaching the investigators who use the library about their own subjects or how to conduct their investigations. Ordinarily, this would be supererogation. The specialist's duty -would be to point out the resources of the library and to make sure that no important body of material is overlooked through the investigator's unfamiliarity with the library's collections. The specialist will see to it, also, that uncataloged or partially cataloged material is made available. For those carrying on research who are already familiar with the library and its resources and do not need to be directed to them, the subject specialist can do much to smooth the way whenever there is need of help in matters that touch library methods and routine. A request might come to place an order for a book; it might be to unravel a complicated bit of cataloging or classification; it might be to introduce order or improvement in what has been done, thus making the collections more usable. The chief object to be attained is to make clear to the serious investigator who uses the library that there is a desk in the library, with an intelligent person behind it, where any library matter concerning the field of research in question will be promptly and knowingly considered, and the needed information given; a desired routine put through; or the matter referred to some higher authority when it transcends the authority of the specialist, as the case may be. There will be no necessity for the outsider to hunt up the order clerk for one matter, the stack chief for another, the catalog chief for a third, the serial division for a fourth, and so on; it will be the subject specialist who will make contact with the necessary officers, unless, indeed, the matter is so important that direct conferences are needed. It may be repeated, also, that only the unusual matter and the more serious investigator need ordinarily be directed to the subject specialist. Such questions as may with certainty be adequately handled by the department first approached should be disposed of at once, thus saving the time not only of the questioner but of the specialist.

\section{A Definite Saving}

Experiments indicate that after an assistant has become conversant with her duties in the several processes there is a definite saving of money by thus combining 
the order and cataloging processes. Adding reference work to these duties does expose the assistant to outside interruptions, but, if someone in the library's pay is to be thus interrupted on a serious matter, efficient administration points to its being the person who can most competently attend to it. Who is this, if not the subject specialist? Moreover, a truly competent assistant will learn to evade the unessential interruptions, while surely service given is of far higher quality when given by one who can be confident that she knows all the moves made by the librarian in her field, who is intimately familiar, not only with the resources of the library that are already accessioned, but who has under her control whatever comes in from day to day, or that is in process of absorption.

\section{New Problems of Organization}

Some new problems of organization may arise in a staff built on this plan. Unless the librarian, himself, can find time to look intimately after details (and this would seem doubtful) there should be an administrative officer, outranking the department heads, who will be given authority to coordinate the work of the special subject assistants and the so-called process departments. It will frequently be necessary to get persons together to decide on just how a certain matter shall be done, how help shall be equitably assigned, when some assistant is rushed by unexpected claims on her time, and to decide what topics are so live and important as to demand the service of a special subject assistant, since, in a large library, subjects rise and wane in importance, depending on changes in the faculty, in courses offered, assignment of funds, or new subjects coming to the front.

It is well, in closing, strongly to em- phasize the idea that these subject specialists are not primarily "catalogers", and should not be so called; nor are they persons whose sole equipment is a knowledge of the subject field, without the technical skill of the cataloger and classifier. They combine the two aspects in happy fashion, making up for a possible lack of deeper knowledge of a subject by their constant and close contacts with faculty members interested in the library, and by a greater willingness to devote themselves to the minutiae of technical processes, which prevent the large library from falling into chaos. Their functions transcend the bounds of the old-fashioned departments, although they must act in complete harmony with those who supervise the processes of ordering and with those who attend to the demands of the public in person or by correspondence, just as they must also be particularly in touch with those who are responsible for the development of the classification and cataloging systems of the library. They are presumably rational and competent beings, who, from ability, character, training, and experience are able to look very much out for themselves and their assistants and who are constantly coordinated in their duties by the senior officer of high rank already mentioned.

It is particularly important that these specialists shall not be submerged in a huge department if such submersion means that they must constantly and arbitrarily be withdrawn from their normal duties to meet some insistent demand of the moment, not germane to their specialties. They should look on their specialties as the prime duty and be given time, opportunity, and authority to handle the material in their care in such fashion as to

(Continued on page 37) 
thekswissenschaft. I. bd. Harrassowitz, Leipzig, 1931.

Writing (Ideogrammatic and Alphabetic Systems): General Works on Philology and Treatises on Special Subjects

Bloomfield, Leonard. Language. Holt, New York [ci933].

Conference on phonetic transcription and transliteration, Copenhagen, 1925. "Phonetic transcription and transliteration; proposals of the Copenhagen conference, April 1925." Oxford, 1926.

International institute of intellectual cooperation. "L'adoption universelle des caractères latins." Sociéte des nations, Institut international de coopération intellectuelle, Paris, I934.

Jensen, Hans. Die Schrift in Vergangenheit und Gegenwart. J. J. Augustin, Glückstadt und Hamburg, [1935].

Twaddell, W. F. On Defining the Phoneme. Waverly press, Baltimore [1935]. (Language monographs, pub. by The Linguistic society of America, no. I6.)

\section{The Western Book}

Wroth, L. C., ed. A History of the Printed Book, Being the Third Number of The Dolphin. ... The limited editions club, New York, 1938.

\section{The Subject Specialist}

\section{(Continued from page 2I)}

make it increasingly useful to those patrons of the library who are engaged in serious research. These considerations, however, will not prevent the assignment, from time to time, of some lesser field of research to a person whose main work may be general and miscellaneous in character.

With a view, then, to smoothing the path for those investigators who use our

\section{The Book of Classical Antiquity}

Birt, Theodor. Kritik und Hermeneutik nebst Abriss des antiken Buchwesens. Beck'sche verlagsbh., München, 1913.

Gardthausen, V. E. Das Buchwesen im Altertum und im Byzantischen Mittelalter. 2. aufl. Veit, Leipzig, I9II. (Griechische Palaeographie. I. bd.)

\section{The Latin Script}

Steffens, Franz. Lateinische Paläographie. . . 2. verm. aufl. W. de Gruyter, Berlin und Leipzig, 1929.

\section{The Influence of the Manuscript}

Ullman, B. L. Ancient Writing and Its Influence. Longmans, New York, 1932.

\section{The Discovery of Printing and Incu- nabula}

Haebler, Konrad. Handbuch der Inkunabelkunde. Hiersemann, Leipzig, 1925.

Scholderer, Victor. Gutenberg: the Man and His Invention. (Issued by The London Times, Jan. 5, 1940.)

Uhlendorf, B. A. The Invention of Printing and Its Spread till 1470. (In The Library Quarterly, 2:179-231, July, I932.)

libraries, decreasing administrative costs, giving sympathetic service, and expanding the opportunity for satisfying and constructive work to the more ambitious and capable members of the staff, the principle of division of work by subject as against division by process should receive the careful attention of the administrators of our large university and reference libraries. 